\title{
Evolving mass spectra of the oxidized component of organic aerosol: results from aerosol mass spectrometer analyses of aged diesel emissions
}

\author{
A. M. Sage, E. A. Weitkamp, A. L. Robinson, and N. M. Donahue \\ Center for Atmospheric Particle Studies, Carnegie Mellon University; Pittsburgh, PA 15213, USA
}

Received: 5 June 2007 - Published in Atmos. Chem. Phys. Discuss.: 11 July 2007

Revised: 18 January 2008 - Accepted: 31 January 2008 - Published: 28 February 2008

\begin{abstract}
The species and chemistry responsible for secondary organic aerosol (SOA) formation remain highly uncertain. Laboratory studies of the oxidation of individual, high-flux SOA precursors do not lead to particles with mass spectra (MS) matching those of ambient aged organic material. Additionally, the complexity of real organic particles challenges efforts to identify their chemical origins. We have previously hypothesized that SOA can form from the atmospheric oxidation of a large suite of precursors with varying vapor pressures. Here, we support this hypothesis by using an aerosol mass spectrometer to track the chemical evolution of diesel exhaust as it is photochemically oxidized in an environmental chamber. With explicit knowledge of the condensed-phase MS of the primary emissions from our engine, we are able to decompose each recorded MS into contributing primary and secondary spectra throughout the experiment. We find that the SOA becomes increasingly oxidized as a function of time, quickly approaching a final MS that closely resembles that of ambient aged organic particulate matter. This observation is consistent with our hypothesis of an evolving suite of SOA precursors. Low vapor pressure, semi-volatile organic emissions can form condensable products with even a single generation of oxidation, resulting in an early-arising, relatively less-oxidized SOA. Continued gas-phase oxidation can form highly oxidized SOA in surprisingly young air masses via reaction mechanisms that can add multiple oxygen atoms per generation and result in products with sustained or increased reactivity toward $\mathrm{OH}$.
\end{abstract}

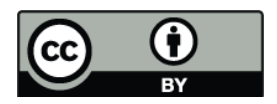

Correspondence to: N. M. Donahue (nmd@cmu.edu)

\section{Introduction}

Based on available emissions profiles and laboratorygenerated yield curves, secondary organic aerosol (SOA) has been estimated to comprise around $60 \%$ of the global burden of organic aerosol (OA) (Kanakidou et al., 2005). A recent global mass-balance calculation for the removal of volatile organic compounds (VOCs) from the atmosphere suggests that this estimate underpredicts SOA production rates by as much as an order of magnitude (Goldstein and Galbally, 2007). Ambient data from major urban areas in North America, Europe and Asia support this higher result, indicating that SOA concentrations downwind of anthropogenic sources are considerably greater than current models predict (de Gouw et al., 2005; Johnson et al., 2006; Heald et al., 2005; Volkamer et al., 2006; Zhang et al., 2007).

Discrepancies between modeled and measured SOA formation are not limited solely to concentration differences; the kinetics and products of SOA-generating chemistry are also problematic. Inexplicably high mass loadings of oxidized organic aerosol (OOA) in photochemically young air masses in Mexico City indicate that SOA formation is rapid enough that SOA can be the dominant component of OA there, even locally, at certain times of day (Volkamer et al., 2006). The oxidation chemistry of the high-flux VOCs that have traditionally been included in models as SOA precursors cannot explain these observations. Nor do chamber studies of the SOA resulting from these precursor produce particulate matter with mass spectra (MS) matching those of ambient OOA (Alfarra et al., 2006; de Gouw et al., 2005).

Taken together, these observations point to serious deficits in our understanding of the chemical nature of SOA, making

Published by Copernicus Publications on behalf of the European Geosciences Union. 
it a relatively poorly characterized contributor to atmospheric aerosol. In response, efforts have been made to speciate ambient OA (Schauer et al., 1999; Rogge et al., 1993; Williams et al., 2006). However, these efforts are challenged by the complexity of the samples, which have been shown to contain tens of thousands of compounds (Hamilton et al., 2004), with the molecular identity of the majority of the organic mass still unknown. Molecular-level approaches confirm that SOA is the product of complicated, uncontrolled radical chemistry that results in compositionally complex particles; the identities of the individual compounds are unlikely to unambiguously indicate their origins. Consequently, there is a need for physically meaningful parameterizations that will allow this chemistry to be efficiently and accurately incorporated into atmospheric chemistry models.

Due to this need, investigations of the chemical nature of bulk SOA are also underway. Recent advances in aerosol mass spectrometry have yielded a wealth of information about the composition of ambient particles. However, the time-averaged sampling necessary to generate acceptable signal and the high-energy ionization methods standard to mass spectrometry, when combined with the complexity typical of atmospheric organics, result in spectra that cannot be deconvolved to a molecular level. Still, considerable progress has been made in determining the properties of OA based on its total signal. For example, laboratory studies have confirmed the formation of "oligomeric" oxidation products with masses several times those of the reactants (Kalberer et al., 2004). Combined thermal desorption and aerosol mass spectrometry provides insight into the vapor pressures of particle constituents (Chattopadhyay et al., 2001). And, several mathematical methods for the analysis of bulk spectra, informed by existing knowledge of atmospheric organic chemistry, can classify organic material by source, functionality, and oxidation state (Bahreini et al., 2005; Marcolli et al., 2006; Zhang et al., 2005a; Lanz et al., 2007).

Zhang et al. (2005b) have convincingly applied one such method to ambient data collected during the Pittsburgh Air Quality Study. Their approach, employing a custom principal component analysis (CPCA), mathematically deconvolves the organic MS from an Aerodyne quadrupole aerosol mass spectrometer (Q-AMS) into two time-invariant factors: hydrocarbon-like organic aerosol (HOA) and oxygenated organic aerosol (OOA). These two factors combine to explain 99\% of the variance in the Pittsburgh data set. Additionally, they show the temporal trends of HOA to be strongly correlated with those of elemental carbon, $\mathrm{NO}$, and $\mathrm{CO}$, indicating that HOA is associated with primary emissions; OOA is similarly correlated with sulfate, suggesting that it constitutes SOA. Results from other locations have also demonstrated success using similar approaches (Zhang et al., 2007; Kondo et al., 2007). Interestingly, the OOA component derived from the CPCA method is not the MS of SOA formed in typical chamber experiments, suggesting that these experiments are not accurately reproducing either the species or the chemistry involved in ambient SOA formation. This points to the need for laboratory SOA experiments carried out under more atmospherically relevant conditions.

In response, we have exposed whole diesel exhaust (vapors and particles), without explicit knowledge of its molecular composition, to atmospheric oxidants in an environmental chamber. The goal of this paper is to use Q-AMS data to characterize the chemistry of SOA formation from the UVinitiated oxidation of this exhaust. A unique advantage of these experiments is that we know the spectrum of the primary organic aerosol (POA) because it is monitored prior to the initiation of chamber chemistry. With this knowledge, we are confident that we can remove the POA spectrum from the total organic MS with fidelity.

In these experiments, SOA was formed rapidly and in high concentrations (Robinson et al., 2007; Weitkamp et al., 2007). Here, we carefully consider the the MS of this SOA. We track the evolution of the MS in time and discuss what that evolution suggests about the species and chemistry driving SOA formation. We compare this MS to the OOA MS derived from the CPCA method to reconcile the timedependence observed in our SOA with the time-invariant OOA component used to describe ambient data. And, we evaluate the atmospheric relevance of our experiments by comparing the composition of our oxidized OA to that of ambient aged OA.

\section{Methods}

The experiments discussed here have been described in detail in a companion publication (Weitkamp et al., 2007). Briefly, several experiments were conducted to observe UV-initiated oxidation chemistry of diesel exhaust in the Carnegie Mellon University smog chamber. The chamber (described in detail in Huff Hartz et al., 2005; Presto et al., 2005) is comprised of a $10 \mathrm{~m}^{3}$ Teflon bag filled with clean, dry air. The bag is suspended in a temperature-controlled room banked with UV lights. In these experiments, small amounts of exhaust from a single-cylinder diesel generator (Yanmar) operated under several engine loads were added to the chamber. After injection of the exhaust, the UV lights in the chamber were turned on to initiate oxidation. The chamber was held at $23^{\circ} \mathrm{C} \pm 1{ }^{\circ} \mathrm{C}$ and $\sim 5 \%$ relative humidity. The evolution of the resulting aerosol was observed for several hours using a Q-AMS (Aerodyne Research, Inc.), a scanning mobility particle sizer (SMPS, TSI 3080), and a proton transfer reaction mass spectrometer (Ionicon).

In each experiment we observed significant particle growth after illumination - in most cases the wall-loss corrected particle mass roughly doubled after a few hours. We observed ten times more SOA than we expected based on oxidation of volatile aromatic precursors such as trimethyl benzene (Weitkamp et al., 2007). Our conclusion, discussed 
elsewhere, is that oxidation of semi-voltile gas-phase species is responsible for this mass increase (Robinson et al., 2007).

Here we wish to explicitly consider the chemical nature of the SOA that was formed. Toward this end, the composition of the non-refractory portion of the diesel particulate matter was monitored using a Q-AMS. The Q-AMS alternated between operating in mass spectrum (MS) scanning mode and in particle time-of-flight (PToF) mode every fifteen seconds (Jayne et al., 2000; Jimenez et al., 2003). The sample averaging time was five minutes, and the vaporizer temperature was $600^{\circ} \mathrm{C}$. This instrument has unit mass resolution, and therefore cannot distinguish among fragments with the same integer mass.

\subsection{AMS data interpretation}

The AMS data were analyzed using the standard fragmentation and batch tables, with corrections applied for particle mass appearing at a mass-to-charge ratio $(\mathrm{m} / \mathrm{z})$ of 28 and for increased gas-phase $\mathrm{CO}_{2}$ concentrations when necessary (Allan et al., 2004a,b).

The AMS signal at $m / z=28$ is normally attributed entirely to gas-phase $\mathrm{N}_{2}^{+}$. This signal is used as an internal standard to quantify and correct for normal electron multiplier degradation over the course of a study. However, organic compounds that produce either $\mathrm{CO}^{+}$or $\mathrm{C}_{2} \mathrm{H}_{4}^{+}$fragments can also produce signal at $m / z=28$. In order to both accurately report the organic mass and reliably apply the multiplier-decay correction, we must properly apportion the observed signal between the gas and condensed phases. To facilitate this apportionment, we sample chamber air through a HEPA filter for at least 20 minutes prior to and after each of our experiments. We attribute the signal at $m / z=28$ during these filter samples entirely to $\mathrm{N}_{2}^{+}$, and we use it to quantify the magnitude of the multiplier decay over the course of the experiment. Additionally, we include $m / z=28$ on our list of masses monitored in PToF mode. Using these PToF data, we can plot $\mathrm{d} m / \mathrm{d}\left(\log D_{v a}\right)$ versus $\log \left(D_{v a}\right)$ (where $D_{v a}$ is the vacuum aerodynamic diameter) and observe a bimodal size distribution. We integrate these curves to find the fraction of the mass at $m / z=28$ in the particle-phase throughout an experiment. We attribute this fraction of the mass recorded at $m / z=28$ to the organic MS; the balance of the mass is attributed to gas-phase $\mathrm{N}_{2}^{+}$. This allows us to constrain the shape of the multiplier decay curve between the two HEPAfilter sampling periods.

The signal appearing at $m / z=44$ is normally apportioned assuming a constant atmospheric $\mathrm{CO}_{2}$ abundance of $370 \mathrm{ppm}$, but engine exhaust can have considerably higher $\mathrm{CO}_{2}$ concentrations. We rely heavily on the organic signal at $m / z=44$ in our analysis, and so adjusted this fraction to ensure that we reliably attributed the observed signal. The gas-phase $\mathrm{CO}_{2}$ concentration in the chamber was found by attributing the entire signal at $m / z=44$ during the post-experiment HEPA sampling period to gas-phase $\mathrm{CO}_{2}$.
This concentration (corrected for multiplier degradation) was taken to be representative of concentrations throughout the experiment. $\mathrm{CO}_{2}$ concentrations varied from 350 to $640 \mathrm{ppm}$ in the experiments discussed here. These concentrations make gas-phase $\mathrm{CO}_{2}$ a minor contributor $(<1 \%)$ to the total mass at $m / z=44$, so we do not expect our results to be sensitive to this correction.

With higher resolution data, it would be possible to consider additional corrections to the fragmentation table. For example, there is undoubtedly organic signal at $m / z=30$ due to $\mathrm{CH}_{2} \mathrm{O}^{+}$, which is currently being attributed to nitrate. We cannot quantify this signal because the AMS-fragmentation pattern for $\mathrm{NO}_{3}$ originating from organic nitrates is unknown. This hampers our ability to quantify organic nitrate formation, a potentially interesting source of early-forming SOA, in these experiments.

All of the spectra presented here are normalized by total organic mass to facilitate comparisons among experiments and methods. Differences in the collection and ionization efficiencies between primary and secondary organics may exist, but this normalization eliminates any need to explicitly consider these variations with particle composition.

\subsection{Decomposition of organic MS}

The MS recorded by the Q-AMS are time- and spatiallyaveraged composite spectra of a complex mixture of hundreds of chemical compounds, which are further complicated by the fragmentation characteristic of the hightemperature vaporization and electron-impact ionization of organic species. The deconvolution of these spectra into individual chemical components is an overwhelmingly difficult task, and we instead aim to describe the chemical evolution of the SOA that is formed from properties of the bulk spectra.

We use two methods to decompose the bulk organic MS into reduced and oxidized components. The first is our residual analysis method, described below, and the second is the CPCA method of Zhang et al. (2005a). In our residual analysis method, we exploit the advantage provided by the controlled nature of a smog-chamber study: it is a batch process with a known POA MS. Using this primary MS (MSPOA) and assuming that the chemical composition of the POA remains constant throughout the experiment, we can obtain the MS of the secondary material $\left(\mathrm{MS}_{\text {residual }}\right)$ that is formed during the experiment by subtracting the known $\mathrm{MS}_{\mathrm{POA}}$ from the observed total spectrum at time $t$ :

$\mathrm{MS}_{\text {residual }}=\mathrm{MS}_{t}-f_{57} \mathrm{MS}_{\mathrm{POA}}$

where $f_{57}$ is the maximum fraction of $\mathrm{MS}_{\mathrm{POA}}$ that can contribute to $\mathrm{MS}_{t}$. We define $\mathrm{MS}_{\mathrm{POA}}$ as the MS recorded prior to the initiation of oxidation at time $t_{o}=0$, and assume that it is an invariant and known component of the total MS at each subsequent time $t . f_{57}$ is calculated as:

$f_{57}=\frac{m_{m / z=57}(t)}{m_{m / z}=57\left(t_{o}\right)}$ 
where $m_{m / z}=57$ is the mass appearing at a $m / z=57$ in the organic MS. Values of $f_{57}$ slightly exceeding unity occasionally occur in the first few samples after the chamber lights are turned on and are attributed to incomplete mixing in the chamber. This residual analysis method of apportioning organic mass between primary and secondary material is in good agreement with independent wall-loss estimates from SMPS data, as shown below.

We have also applied the CPCA method of Zhang et al. (2005a) to data from these experiments (Zhang, 2005). This method deconvolves observed organic mass spectra into two factors: HOA and OOA. These component MS are determined iteratively, starting from an initial guess based on the time series of the organic mass appearing at representative peaks $(m / z=57$ and $m / z=44$, respectively, for HOA and OOA) that is refined based on the results of multiple multivariate linear regressions. The MS observed at any time during an experiment can be expressed as a linear combination of the resulting HOA and OOA spectra for that experiment.

Both apportionment methods provide insight into the chemical processes occurring in the chamber. However, there is a fundamental difference: the two factors (HOA and OOA) in the factor analysis method are, by definition, constants, with a time-evolving mixing term that describes the temporal evolution of the overall mass spectrum; on the other hand, in the residual analysis method $\mathrm{MS}_{\mathrm{POA}}$ is a constant, fixed at its initial value, but $\mathrm{MS}_{\text {residual }}$ can and does evolve in time.

\subsection{Uncertainties involved in the residual analysis method}

Implicit in our use of a single MS peak as a scaler for the entire $\mathrm{MS}_{\mathrm{POA}}$ is the assumption that the initially recorded MS accurately represents the chemical composition of the condensed fraction of the primary emissions throughout an experiment. This assumption excludes consideration of spectral changes due to both repartitioning of primary emissions and condensed-phase chemistry. The first exclusion we can validate based on our observations that the MS $\mathrm{POA}_{\mathrm{P}}$ from the engine used in these experiment varies little between experiments and control experiments that show that it changes negligibly in the absence of light. Over the conditions of these experiments (initial mass concentrations of 5 to $80 \mu \mathrm{g} / \mathrm{m}^{3}$, as measured by the SMPS assuming spherical particles with a density of $1 \mathrm{~g} \mathrm{~cm}^{-3}$ ), changes in partitioning do not appear to affect the basic features of the averaged MS $\mathrm{POA}_{\mathrm{PO}}$.

The second assumption is more difficult to evaluate. Ambient observations of molecular-marker decay and laboratory studies of the heterogeneous reactions in organic particles suggest that condensed-phase primary organics are oxidized under atmospheric conditions (Robinson et al., 2006; Rudich et al., 2007). However, in their analysis of OA in Pittsburgh, Zhang et al. (2005b) show a strong correlation between OOA and sulfate concentrations, indicating that the OOA signal is primarily due to SOA, not oxidized POA. Here, we assume an invariant $\mathrm{MS}_{\mathrm{POA}}$, but small changes in this spectrum due to, for example, heterogeneous processing, could affect the apportionment of organic aerosol between primary and residual components. We can estimate the potential effects of heterogeneous oxidation by assuming that it is dominated by $\mathrm{OH}$ uptake. With an $\mathrm{OH}$ uptake coefficient of unity, $100 \mathrm{~nm}$ particles with a density of $1 \mathrm{~g} \mathrm{~cm}^{-3}$ and a mean molar mass of $150 \mathrm{~g} \mathrm{~mol}^{-1}$ would have a lifetime with respect to $\mathrm{OH}$ oxidation on the order of 2 days in our experiments. Therefore, at the conclusion of a 5 -h experiment, no more than $12 \%$ of the POA should be oxidized.

Accounting for either partitioning or heterogeneous oxidation would increase the fraction of the material identified as primary, and decrease the fractional contribution of oxidation marker peaks, such as $m / z=44$, to the $\mathrm{MS}_{\text {residual, making it }}$ appear relatively less oxidized. However, based on our control experiments and our knowledge of the oxidation conditions in the chamber, we cannot explain our results in terms of these two phenomena. Neither shows an effect within an order of magnitude of the changes we observe.

The use of $m / z=57$ as the single marker peak that dictates how much of a given MS is attributed to primary material is in general agreement with the identification of $m / z=57$ by Zhang et al. (2005a) as the single best tracer for HOA based on a combination of its intensity and unique source $\left(\mathrm{C}_{4} \mathrm{H}_{9}^{+}\right)$ in the MS of combustion exhaust. However, beyond its welldocumented correlation with anthropogenic POA, our choice of $m / z=57$ is purely phenomenological: it is the first MS peak to reach zero when we progressively increase the fraction of MSPOA that is subtracted from the observed total MS (Zhang et al., 2005a; Canagaratna et al., 2004). Ambient data suggest that attributing all of the signal at $m / z=57$ may overestimate the contribution of POA. Application of the CPCA method in field campaigns has found that oxidized organic material has a signal at $m / z=57$ that is between $2 \%$ and $6 \%$ of that at $m / z=44$ (Zhang et al., 2005b). In our experiments, we find that reducing the amount of MS $\mathrm{SOA}_{\mathrm{POA}}$ subtracted from $\mathrm{MS}_{t}$ to meet this criterion results in only a slightly less oxidized $\mathrm{MS}_{\text {residual }}$; the change in $f_{57}$ is on the order of $1 \%$.

\section{Results and Discussion}

In each of the experiments discussed here, the MS of the condensed phase changes with time. The fractions of the total organic mass appearing at $m / z=44\left(\mathrm{CO}_{2}^{+}\right)$and $31\left(\mathrm{CH}_{3} \mathrm{O}^{+}\right)$, two masses that are indicative of oxidized material, increase with time, while the fractions appearing at masses associated with reduced organic material, such as $m / z=57\left(\mathrm{C}_{4} \mathrm{H}_{9}^{+}\right)$and $71\left(\mathrm{C}_{5} \mathrm{H}_{11}^{+}\right)$, decrease (Zhang et al., 2005a). From the increasingly oxidized nature of the condensed-phase material and accompanying observations of increases in its mass, we conclude that substantial amounts of SOA are formed from the oxidation of diesel emissions (Weitkamp et al., 2007). 

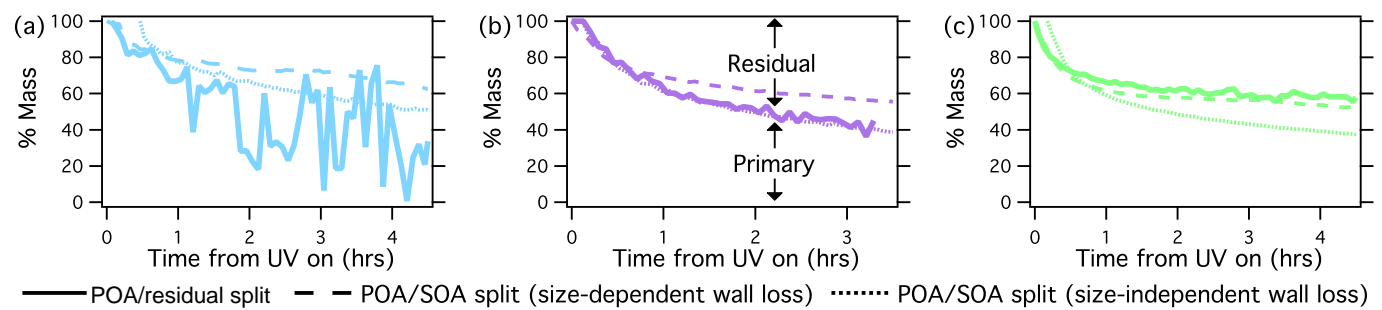

Fig. 1. Results of the organic mass apportionment from the residual analysis method for three experiments: (a) low $\left(6.5 \mu \mathrm{g} \mathrm{m}{ }^{-3}\right),(\mathbf{b})$ medium $\left(10.2 \mu \mathrm{g} \mathrm{m}^{-3}\right)$ and (c) high $\left(68 \mu \mathrm{g} \mathrm{m}^{-3}\right)$ initial aerosol mass concentrations. Masses are reported from SMPS data assuming spherical particles with a density $1.0 \mathrm{~g} \mathrm{~cm}^{-3}$. Results from an inverse wall-loss model are also shown. Dotted lines assume wall loss rates to be independent of particle size while dashed lines explicitly incorporate a size-dependence.

\subsection{Decomposition of organic MS}

Using the residual analysis method in Eqs. (1) and (2), the decomposition of the organic mass into primary and residual components in three different experiments is shown by the solid lines in Fig. 1. The three experiments vary in both initial mass concentrations of primary aerosol and engine loads. Each experiment, however, shows the same trend. Within 15 minutes of the initiation of oxidation, the primary MS fraction begins to diminish. Within $1 \mathrm{~h}$, the primary MS only accounts for $70 \%$ of the observed organic mass. The primary MS fraction continues to decline throughout the experiments, though at a slowing rate, until, after $3 \mathrm{~h}$, only between 30 and $60 \%$ of the observed mass is primary.

We wish to verify that the residual analysis gives us a reasonable POA/SOA split, but as in all static chamber experiments, uncertainties in the wall-loss rates limit our accuracy. Direct observation of wall loss in these experiments is confounded by concurrent SOA production. Using SMPS data and an inverse model (Aerosol Parameter Estimation model: APE), we have estimated wall losses in the chamber during these experiments (Pierce et al., 2007 ${ }^{1}$ ). The APE model allows us to explicitly calculate the primary mass in the chamber. With this we can apportion the recorded SMPS mass between primary and new (secondary) and then compare this apportionment to the MS-based apportionment. Although both approaches require a number of assumptions (as discussed above and in Weitkamp et al. (2007)), the two methods are independent, and their overall agreement is reasonable. The results are compared in Fig. 1. The discrepancies that do exist suggest that the residual analysis method and wall-loss model estimates of the POA/SOA split converge as aerosol mass increases. At lower aerosol masses, the residual analysis method may underestimate the primary fraction

\footnotetext{
${ }^{1}$ Pierce, J. R., Engelhart, G. J., Weitkamp, E. A., Pathak, R. K., Pandis, S. N., Donahue, N. M., Robinson, A. L., and Adams, P. J.: Constraining particle evolution from wall losses, coagulation, and condensation-evaporation in smog- chamber experiments: optimal estimation based on size distribution measurements, Aerosol Sci. Tech., submitted, 2007.
}

of the organic mass. In the following section, our detailed analysis focuses on the third, highest mass $\left(68 \mu \mathrm{g} \mathrm{m}^{-3}\right) \mathrm{ex}-$ periment where the two approaches are in excellent agreement. Here, we are confident that the residual MS reflects the composition of the SOA that is formed. We will then show that these results are consistent with our observations from and hence generalizable to the other experiments.

\subsection{Evolution of $\mathrm{MS}_{\text {residual }}$}

The time-dependent evolution of the $\mathrm{MS}_{\text {residual }}$ is demonstrated by the results of a typical experiment shown in Fig. 2. In Fig. 2a, the organic mass measured by the Q-AMS is apportioned between primary and residual components as discussed above. The MS of the grey portion is $\mathrm{MS}_{\mathrm{POA}}$. The MS of the green portion is $\mathrm{MS}_{\text {residual }}$; this spectrum evolves in time as indicated in Figs. $2 b$ and c. According to this apportionment, secondary material begins to form immediately after the chamber lights are turned on and accounts for over $10 \%$ of the total organic mass within $15 \mathrm{~min}$. After $5 \mathrm{~h}$, the $\mathrm{MS}_{\text {residual }}$ accounts for approximately $40 \%$ of the suspended organic mass.

One of the most straightforward indicators of the oxidation state of organic aerosol is the mass appearing at $m / z=44$ (Zhang et al., 2005a). The $\mathrm{CO}_{2}^{+}$fragment appearing at this mass is believed to form in the AMS primarily from the degradation of pyrolyzable material on the AMS vaporizer surface. Signal at this mass is a good indicator for OOA and is emerging as a decent surrogate for tracking the $\mathrm{O}: \mathrm{C}$ ratio in unit-resolution instruments (Aiken et al., 2008). Figure 2b shows the percentage of the mass in the $\mathrm{MS}_{\text {residual }}$ appearing at $m / z=44$ as a function of time. This simple metric shows the residual becoming progressively more oxidized over the course of the experiment. The percent of the $\mathrm{MS}_{\text {residual }}$ appearing at $m / z=44$ increases by a factor of three, from $4 \%$ to $12 \%$, during this five-hour experiment. The combination of the residual becoming more oxidized (Fig. 2b) and the decreasing fractional contribution of $\mathrm{MS}_{\mathrm{POA}}$ (Fig. 2a) means that the organic particles are becoming increasingly oxidized with time. 

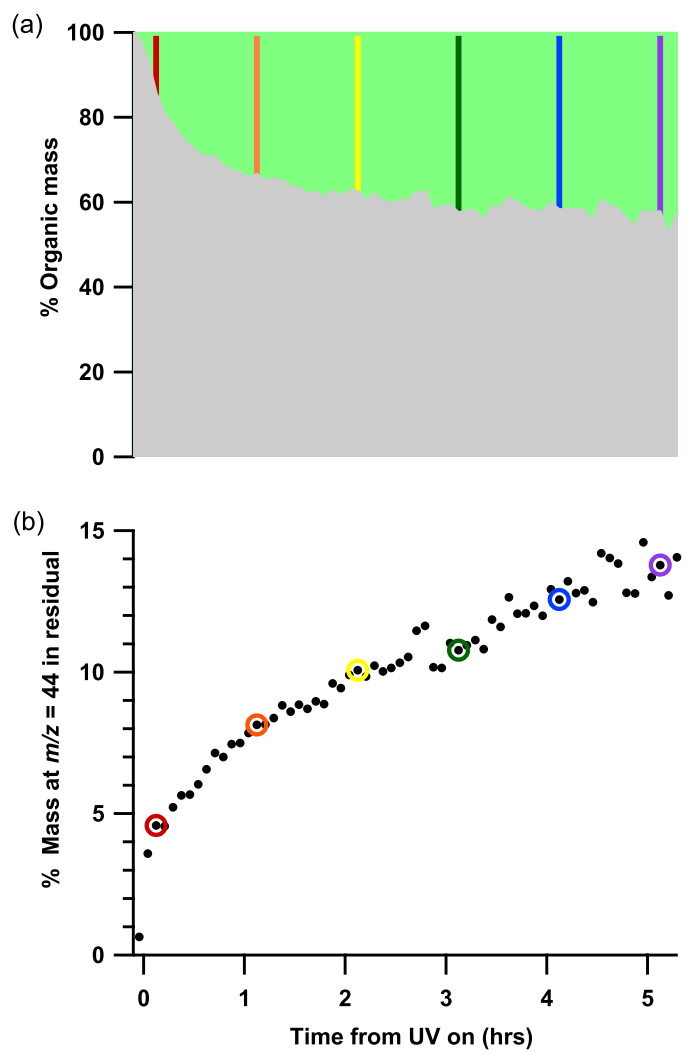

(c)

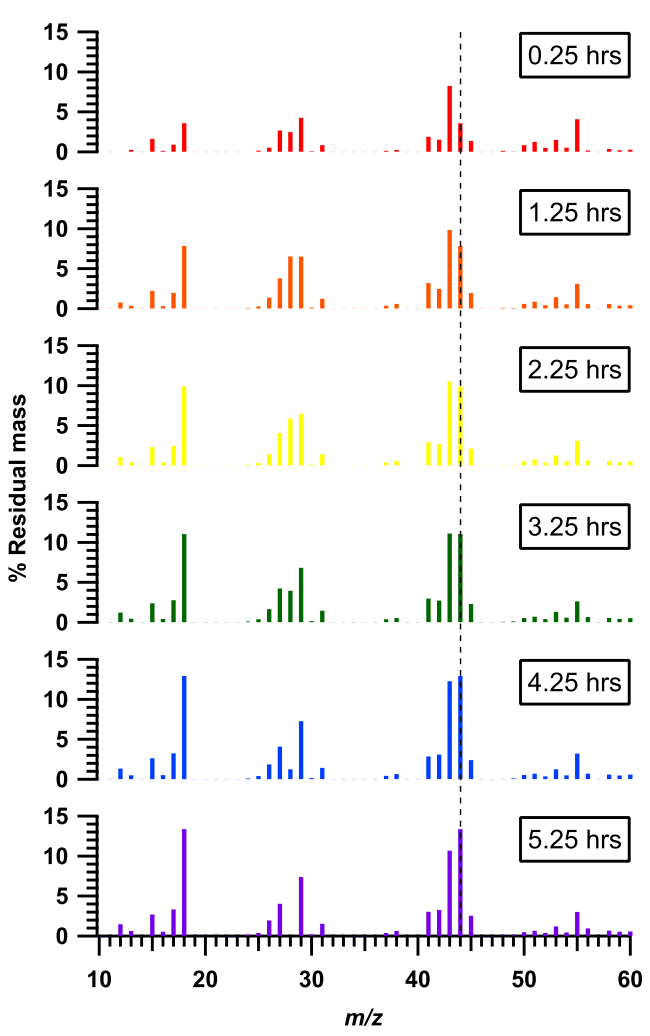

Fig. 2. Results of reisdual anlaysis. (a) Apportionment of organic signal among primary (grey) and residual (green). The MS of the grey portion is constant and is shown in Fig. 4; the evolving MS of the green portion is shown to the right. The colored lines indicate the times for which residual spectra are shown. (b) Percent of the residual MS mass appearing at $m / z=44$ as a function of time. The colored circles indicate the times for which residual spectra are shown. (c) Changes in the residual MS with time starting at $0.15 \mathrm{~h}$ after the initiation of oxidation (bottom, red) and shown every hour until $5.25 \mathrm{~h}$ (purple, top). The dashed line marks $m / z=44$.

Figure $2 \mathrm{c}$ shows the evolving oxidation of the residual fraction of the organic mass in more detail. Six residual spectra are shown at one-hour intervals starting $15 \mathrm{~min}$ after the initiation of oxidation. These times are designated by the colored lines and circles in Figs. 2a and b, respectively; the earliest spectrum is shown in red at the top of the column and the last in purple at the bottom. Two features of the time series of these $\mathrm{MS}_{\text {residual }}$ are readily apparent. The first is that the basic structure of the residual spectrum emerges quickly, being established only $15 \mathrm{~min}$ into the experiment. The dominant peaks in the first $\mathrm{MS}_{\text {residual }}$ remain dominant throughout the experiment. The second is that the ratio of the height of the peak at $m / z=44$ to that at $m / z=43$ (the $44: 43$ ratio) steadily increases throughout the experiment. In the early spectra, $m / z=43$ is the strongest peak, whereas in the later ones it is $m / z=44$ (and $m / z=18$, which is set equal to $m / z=44$ in the fragmentation table used here (Allan et al., 2004a,b)).

Traditional single-precursor SOA experiments often display behavior opposite that observed here (Zhang et al., 2006). In those experiments, terpenes react with ozone at carbon-carbon double bonds, leading to products whose composition does not evolve in time because they are no longer reactive with the oxidant. Increased precursor oxidation simply increases the total product mass without changing the product composition, and the most oxidized SOA is observed to condense first, at the lowest aerosol loadings. This is presumably because the most highly oxidized material generally has the lowest vapor pressure; therefore, it condenses earlier, at the lower OA concentrations. This difference between our current results and those looking at SOA formation from ozonolysis of biogenic precursors strongly suggests that the chemistry occurring in the diesel experiments involves a suite of precursors that form condensable products after varying numbers of oxidation reactions. Our observations match more closely with recent chamber photolysis studies, which also show SOA that is becoming progressively more oxidized with time (Baltensperger et al., 2005). We attribute this to continuing oxidation of semivolatile gas-phase species: when reaction products remain reactive with the oxidant, the gas-phase chemistry will continue until its products are of sufficiently low vapor pressure to condense. 

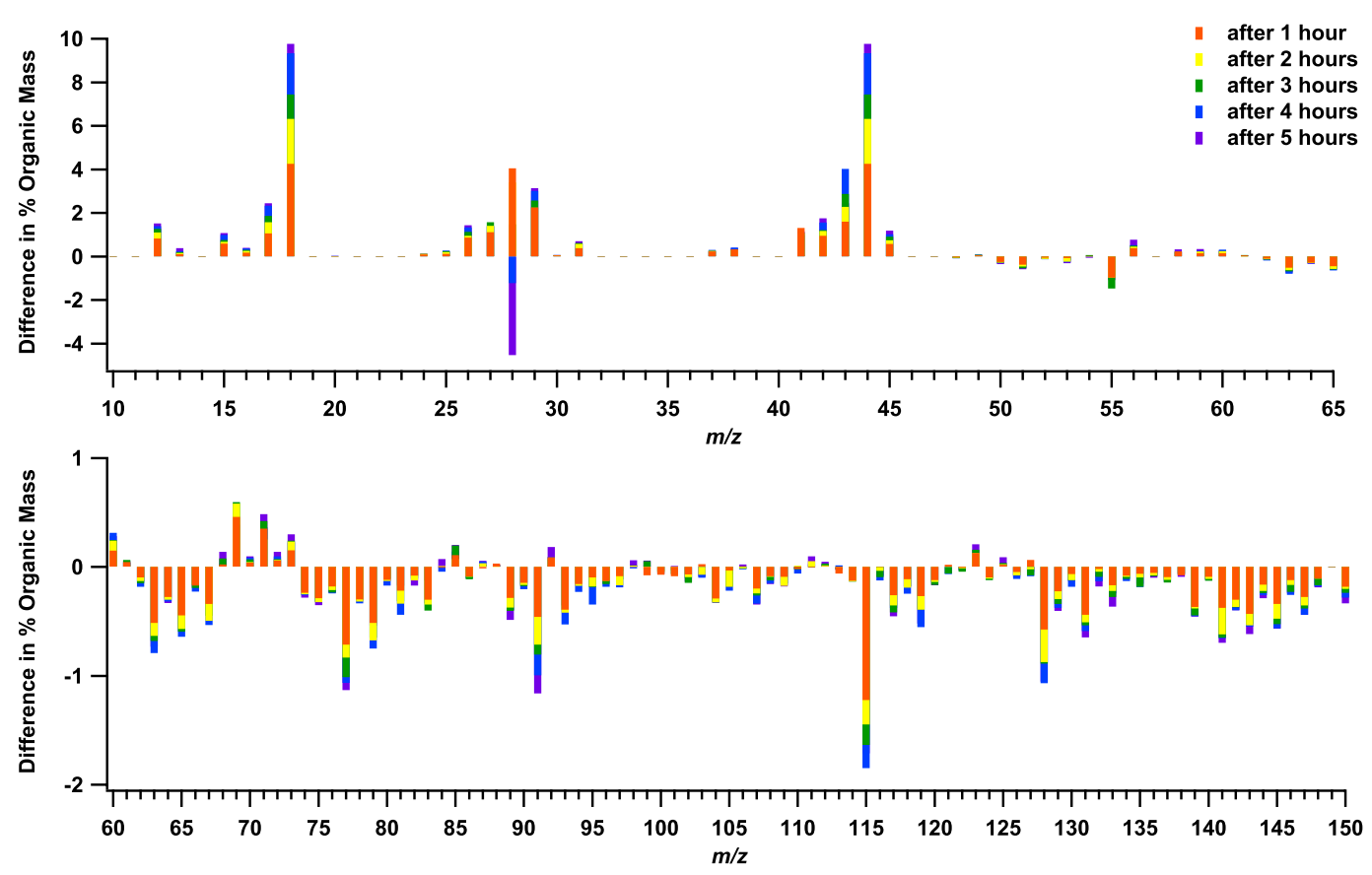

Fig. 3. Detailed evolution of the residual MS as a function of time during a typical experiment. The cumulative changes occurring at each $m / z$ ratio relative to the initial $\mathrm{MS}_{\text {residual }}$ at $t=0.25 \mathrm{~h}$ (in red in Fig. $2 \mathrm{c}$ are shown. The height of a bar indicates the change in the percent contribution at that $\mathrm{m} / \mathrm{z}$ ratio and the color of the bar indicates the time elapsed.

The spectra shown in Fig. 2 are expressed in terms of percentage of the total organic signal, so the relative increase in signals at $m / z=44$ and 18 (more than $15 \%$ of the total organics) must be counterbalanced by corresponding losses elsewhere. These losses are dispersed, appearing as small relative decreases at most masses greater than $m / z=62$. The progressive changes observed in the $\mathrm{MS}_{\text {residual }}$ over the course of this experiment are shown in the difference spectrum in Fig. 3. This spectrum shows the cumulative changes occurring at each $m / z$ ratio relative to the initial $\mathrm{MS}_{\text {residual }}$ at $t=0.25 \mathrm{~h}$, shown in red in Fig. 2c. Masses that are increasing in importance with time are shown as positive; those that are decreasing are negative. Examples of masses of increasing and decreasing importance are $m / z=44$ and 91 , respectively. The height of a bar indicates the change in the percent contribution at that $m / z$ ratio and the color of the bar indicates the time elapsed. For example, the mass appearing at $m / z=44$ is shown in Fig. $2 b$ to increase from $4 \%$ to $14 \%$ of the total organic mass between $t=0.25$ and $t=5.25 \mathrm{~h}$; this $10 \%$ change is indicated by the purple bar at $m / z=44$ in Fig. 3. Masses in Fig. 3 that show the same color progression shown in Fig. 2c are changing systematically with oxidant exposure. Initial increases (shown in orange) followed by subsequent decreases (shown in blue and violet) in the fractional contribution of $m / z=28$ interestingly suggest that the $\mathrm{CO}^{+}$fragment is important in the early, rapid phase of SOA formation, but not as much in the later, slower phase. Overall, this spectrum shows a characteristic typical of increasingly oxidized organic ma- terial: as long carbon chains become more functionalized with oxidation, they are increasingly fragmented by electron impact ionization, and signal in their MS shifts to smaller masses. Hence, small masses become increasingly dominant as oxidation progresses.

Our fundamental conclusions from the data shown in Figs. 2 and 3 are that a large amount of SOA is formed from oxidized diesel emissions and that the MS of that SOA is changing as a function of time. Moreover, our residual analysis indicates that the compounds comprising this SOA are becoming substantially oxidized on surprisingly short timescales. This observation is consistent with ambient observations that show rapid production of relatively oxidized SOA (Salcedo et al., 2006). Based on our knowledge of conditions in the chamber during these experiments, we expect that the observed SOA formation results from a high- $\mathrm{NO}_{x}$, $\mathrm{OH}$-initiated oxidation scheme such as that outlined by Lim and Ziemann (2005). The organic mass was dominated by hydrocarbons, the $\mathrm{OH}$ concentrations were calculated to be $3 \pm 1 \times 10^{6}$ molecules $\mathrm{cm}^{-3}$, and $\mathrm{NO}_{x}$ concentrations, though not measured, were assumed to be high. High- $\mathrm{NO}_{x}$ oxidation of saturated hydrocarbons initiates a rapid sequence of radical reactions and isomerization steps that lead to substantially oxidized, stable products. In this mechanism, a single $\mathrm{OH}$ attack can result in the addition of three oxygen atoms to a saturated hydrocarbon almost immediately. Hence, the oxidation of semivolatile organic vapors can rapidly produce relatively oxidized SOA. 

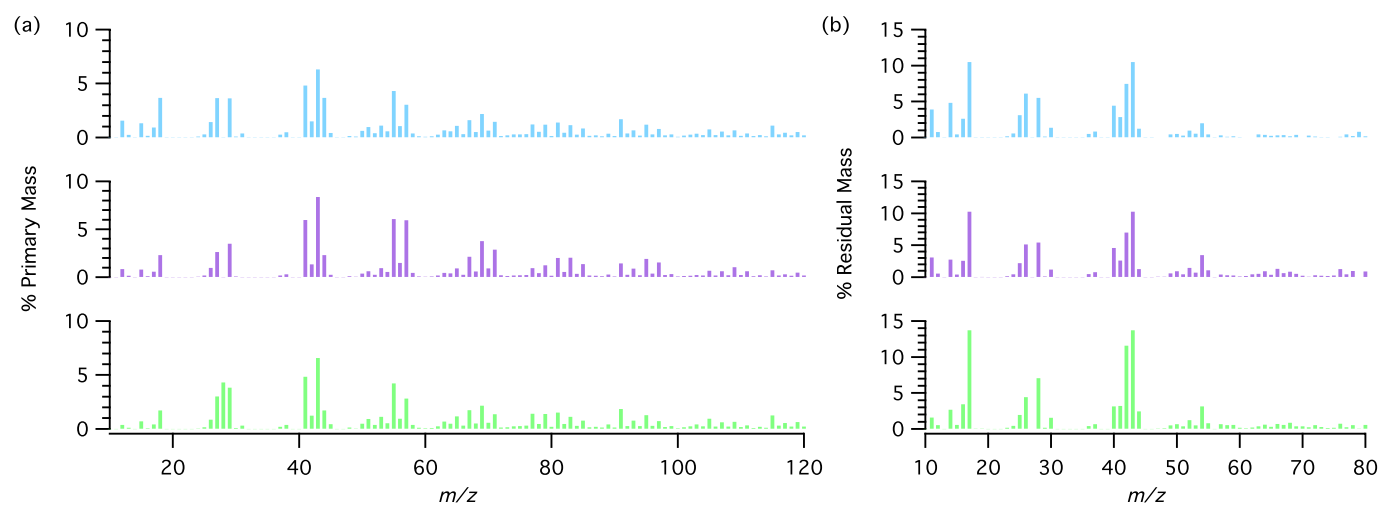

Fig. 4. Variations in the (a) primary and (b) residual spectra among experiments. Colors correspond to the three experiments shown in Fig. 1.

As product oxygen-content increases, volatility will generally decrease (Lim and Ziemann, 2005). If this volatility decrease is sufficient given background aerosol mass loadings, that product will condense to form SOA. The point at which a species' volatility is lowered enough so that it will condense depends strongly on the original precursor's volatility (well-represented in alkanes by the carbon-chain length), the background aerosol mass loading, and the number of generations of oxidation chemistry this precursor has undergone. With time, increasingly volatile precursors (with shorter carbon chains) will have accumulated enough oxygen so that they can condense. Hence, the O:C ratio (represented here by the fraction of the mass appearing at $m / z=44$ ) observed in the particle increases steadily with time both because of the addition of one to three oxygen atoms to a precursor with each generation of gas-phase chemistry and because the length of the carbon backbone capable of condensing decreases with each generation of chemistry.

At the $\mathrm{OH}$ levels present during these experiments and using rate constants typical of large saturated and unsaturated species, one generation of oxidation occurs every 3-5 h (Atkinson and Arey, 2003). Remembering that the generational lifetime refers to the point at which the reactant concentration has dropped to $1 / e$ of its initial concentration (i.e., the chemistry of that generation is nearly complete), it is reasonable to expect that the particles at the end of even these relatively short experiments are comprised of multiple generations of products.

The results shown in Figs. 2 and 3 are typical of those observed in all three experiments. The variations among the $\mathrm{MS}_{\mathrm{POA}}$ and the final $\mathrm{MS}_{\text {residual }}$ in the three experiments are compared in Fig. 4. All three MS $\mathrm{POA}_{\mathrm{P}}$ show patterns characteristic of samples dominated by long alkyl chains. Similar spectra have been observed for fuel and lubricating oil in laboratory studies and for fresh vehicle emissions in New York City chase studies (Canagaratna et al., 2004). This pattern is also characteristic of the HOA-component of ambient spectra analyzed using the CPCA method of Zhang et al. (2005a). It is worthwhile to note, that 2 to $4 \%$ of the mass in our MSPOA appears at $m / z=44$. It is possible that this signal is due to $\mathrm{C}_{3} \mathrm{H}_{8}^{+}$, to pyrolysis or, since engines are oxidizing devices, to some oxidation resulting in a contribution from $\mathrm{CO}_{2}^{+}$. Regardless of its source, there is material at this $\mathrm{m} / \mathrm{z}$ ratio in our primary fraction that is not found in analyses of ambient emissions (Zhang et al., 2005a; Canagaratna et al., 2004). The modest variations among our primary spectra are due, most likely, to changing engine loads, initial mass concentrations, and exhaust injection-port temperatures, but these variations have not been systematically explored.

Figure $4 \mathrm{~b}$ shows the final $\mathrm{MS}_{\text {residual, averaged over the }}$ last five sampling periods ( 25 minutes) of each experiment. Each spectrum has the same basic structure, dominated by the peaks at $m / z=18$ and 44 . All show that the $44: 43$ ratio exceeds unity, though not by as much as in spectra of aged organic material from field studies downwind of Vancouver or in the OOA component of the total spectrum in Pittsburgh (Alfarra et al., 2004; Zhang et al., 2005b). Our data suggest that this ratio continues to increase with time, but our ability to explore this evolution further is limited by loss of mass to the chamber walls. The high mass experiment shown in the bottom panel of Fig. $4 \mathrm{~b}$ was the longest of the three and shows a correspondingly larger mass fraction at $m / z=44$.

\subsection{Analysis method comparison}

The residual analysis method is uniquely suited to laboratory studies, because it requires explicit knowledge of MSPOA. This knowledge, however, provides us with some confidence in attributing our $\mathrm{MS}_{\text {residual }}$ to the SOA being formed in the experiment. Ambient conditions do not easily accomodate measurements of a representative $\mathrm{MS}_{\mathrm{POA}}$, making it necessary to mathematically deconvolve ambient organic MS. Zhang et al. (2005b) have used their CPCA method on data from Pittsburgh, Pennsylvania to convincingly apportion organic aerosol between two components: an oxidized component (OOA) that closely tracks processes associated with SOA formation and a reduced component (HOA) that is well correlated with markers for primary emissions. 

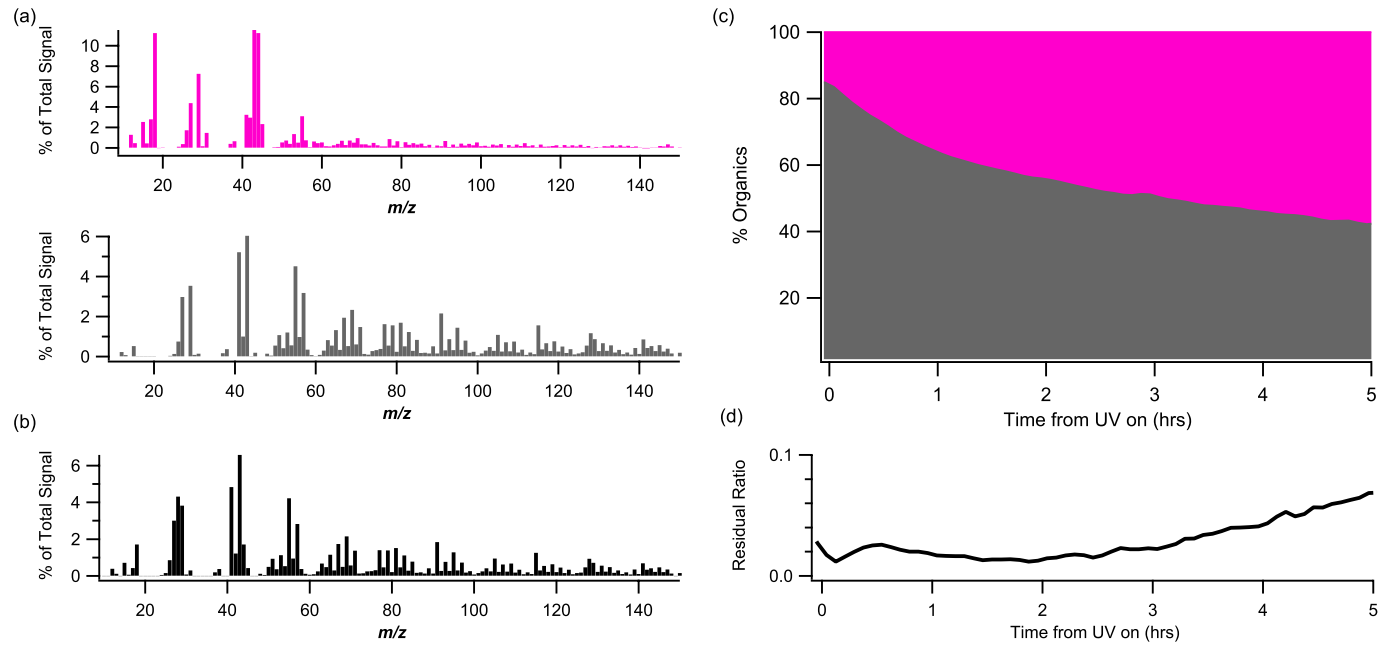

Fig. 5. Results of the CPCA method for the experiment shown in Figs. 2 and 3. (a) The OOA (top, pink) and HOA (bottom, grey) spectra found for this experiment. (b) The primary spectrum measured prior to the initiation of oxidation in the chamber for this experiment. (c) The HOA/OOA split for the experiment shown in Fig. 2. (d) The ratio of the absolute residual of the two factor fit to the the organic mass.

The CPCA method is designed for use in situations where only two components affect the data. In our application of this method, our goal is to determine how well our chamber data can be represented by two constant components: an HOA component representing the POA and an OOA component representing the SOA. Additionally, we are interested in how the components derived from our chamber studies compare to those found in ambient datasets. Wall losses in the chamber complicate this comparison, but thoughtful application of the CPCA method combined with results from our residual analysis provide greater insight into SOA formation.

Figure 5 shows the results of the CPCA method for the same experiment analyzed using the residual method in Figs. 2 and 3. This method describes the total MS observed at any time as a linear combination of the OOA MS (shown in pink) and the HOA MS (in grey) shown in Fig. 5a. While the OOA MS is similar to the final $\mathrm{MS}_{\text {residual }}$ from our residual method (see Fig. 2c), there are key differences. Most significantly, the 44:43 ratio in the OOA spectrum is less than unity. In fact, the OOA MS more closely resembles the $\mathrm{MS}_{\text {residual }}$ much earlier in the experiment. The HOA spectrum is very similar to our primary spectrum, which is shown again in Fig. 5b for reference. Both the HOA MS and $\mathrm{MS}_{\mathrm{POA}}$ display the picket-fence pattern characteristic of primary emissions from fossil-fuel combustion. However, there are again important differences. Most notably, our MS $\mathrm{POA}_{\mathrm{POA}}$ shows a significant $m / z=44$ signal, while the HOA signal at $m / z=44$ is nearly zero. The $m / z=28$ data were not used in the CPCA.

Figure 5c, shows how the CPCA method apportions the mass among OOA and HOA. The apportionment is very similar to that obtained from the residual analysis method (see Fig. 2a), but the amount of OOA determined by the CPCA method is greater than the fraction of material attributed to the residual by a relatively constant offset of 10 to $15 \%$. This offset is due to the differences between our MS $\mathrm{POA}_{\mathrm{PO}}$ and the derived HOA MS, which are most obvious at $m /=44$, and result in the CPCA method apportioning $15 \%$ of the initial MS to OOA. The HOA/OOA division thus lies about $15 \%$ below the primary/residual division, in agreement with our observation that the primary emissions in this experiment had $2 \%$ of their organic mass at $m / z=44$.

The quality of the fit result obtained with the CPCA method is shown in Fig. 5d. This is expressed as the ratio of the absolute residual of the least-squares fit to the total organic mass as a function of time and shows that the reconstruction of the total MS from only two component spectra becomes increasingly poor as the experiment progresses. Even at its worst, this ratio is less than $10 \%$ of total organic mass, suggesting that these two components reproduce more than $90 \%$ of the variation in the recorded spectra, but the systematic increase suggests a trend in these data that is not being captured by this approach.

In order to further investigate this trend, we divided the data into three 105-min sections (designated early, middle, and late) and applied the CPCA method to each section individually. This division allows us to exploit the mathematical rigor of the CPCA method while permitting some time-dependent variation in the resulting components. The three OOA components calculated using this approach are shown in Fig. 6, alongside the results of the residual analysis method, which have simply been averaged over the same time periods. The early OOA MS shown in Fig. 6a, is nearly identical to the OOA MS determined from analysis of the entire dataset (shown in Fig. 5a). However, analysis of the data collected later in the experiment produces a more oxidized OOA component (as measured by the 44:43 ratio). 

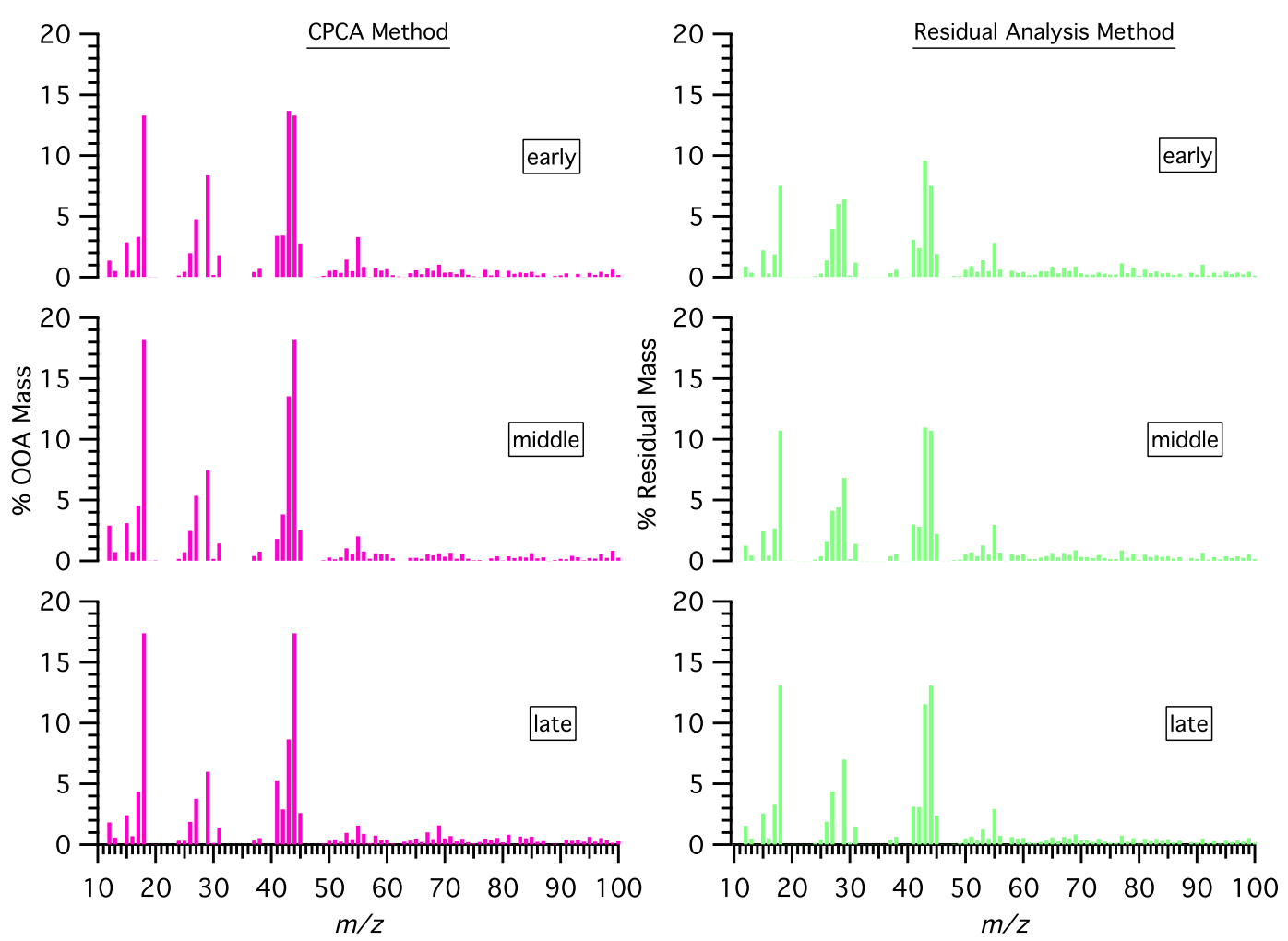

Fig. 6. Results of piecewise analyses performed by breaking the dataset shown in Fig. 2 into three 105-min segments. Shown are the oxidized components of the mass spectrum as calculated by the CPCA (left, pink) and residual (right, green) methods for the early, middle and late periods of the experiment.

Analyzing the data in this piecewise fashion reveals that the 44:43 ratio in the OOA MS increases from approximately 1:1 to more than 2:1 over the course of the 5-h experiment. The HOA spectra (not shown) remain relatively constant over time except for a $2 \%$ increase in the fraction of the HOA mass appearing at $m / z=43$ between the middle and late segments. Reassigning this entire increase in the late HOA $m / z=43$ mass to the late OOA MS would decrease the final $44: 43$ ratio to $1.4: 1$, which is still considerably larger than the ratio determined using the CPCA method when applied to the initial period of the experiment or to the entire dataset.

These piecewise components are better able to reconstruct the observed MS over the course of the experiment. The largest error in any of the three time periods is $3.5 \%$ of the organic mass, again at the end of the last time period. Even with this piecewise approach, there remains a generally increasing trend in the residual ratio over time, both within a single time period and over the course of the experiment. This suggests that further subdivision of the data would continue to show the OOA component becoming progressively more oxidized with time, similar to the results from our residual analysis shown in Fig. 2c.

When viewed using the piecewise approach, the results of the CPCA and the residual analysis agree qualitatively. Both methods show the secondary aerosol becoming pro- gressively more oxidized with time. Both also give MS that are dominated by peaks at $m / z=18\left(\mathrm{H}_{2} \mathrm{O}^{+}\right), 29\left(\mathrm{CHO}^{+}\right), 43$ $\left(\mathrm{C}_{2} \mathrm{H}_{3} \mathrm{O}^{+}\right.$and $\left.\mathrm{C}_{3} \mathrm{H}_{7}^{+}\right)$, and $44\left(\mathrm{CO}_{2}^{+}\right)$. The MS determined by the two methods differ most notably by the percentages of their total mass located at $m / z=44$, which indicate that the OOA component is more oxidized than the final, averaged residual. This difference is likely attributable to the oxidized material that is included in the MS $\mathrm{POA}_{\mathrm{P}}$ according to the residual analysis but attributed to OOA in the CPCA.

Our conclusion from both of these analyses is that the MS of the oxidized component formed from oxidation of diesel emission is evolving in time. This is chemically intuitive: relatively low vapor pressure, gas-phase species should require little oxidation before condensing, whereas more volatile species will require more oxidation and, consequently, more time before they begin to condense under atmospheric conditions. Therefore, we expect and observe different mass spectra from SOA formed earlier and later in this experiment. However, this result appears to run counter to the successful application of the two-component CPCA to ambient data, which describes recorded MS as a linear combination of two time-invariant component spectra and captures the evolution in the total organic MS using a time-dependent mixing term.

The piecewise application of the CPCA method suggests a source for this incongruity. Each successive application of 

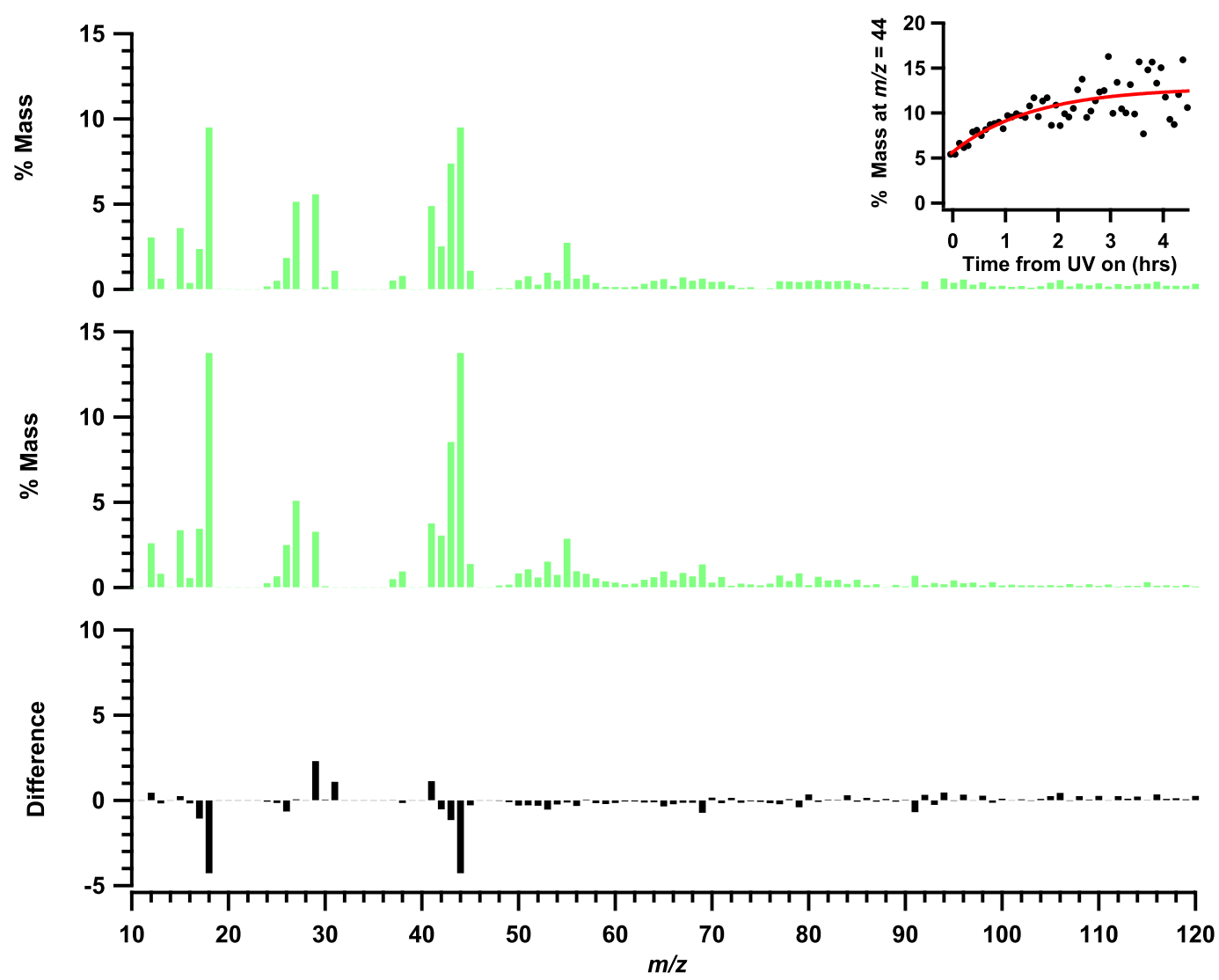

Fig. 7. Comparison between laboratory and ambient spectra. The top panel shows the final organic MS for the low mass experiment with an inset that shows the fraction of the total organic mass appearing at $m / z=44$ as a function of time throughtout the experiment. Red line is an exponential fit. The middle panel shows ambient oxidized aerosol from Alfarra et al. (2004). The bottom panel shows the difference between the two.

CPCA method results in a more oxidized OOA component, while the HOA component remains relatively constant. As SOA continues to form, the 2-component CPCA solution is approaching the type of solution that is typical of its successful ambient application: situations where the two types of organic aerosol present are very fresh, primary material (HOA or POA) and aged, secondary material in a regional air mass (OOA or SOA). When applied to the entire dataset, however, the method results in a substantially less-oxidized OOA component which is remarkably similar to that in the earliest one-third of the experiment. In a chamber experiment, this is the period with the highest mass loading. Because the fit strives to minimize the difference between the recorded and reconstructed MS, it inherently weights periods of high signal where that difference will be the largest.

Our batch, chamber experiments have a well-defined $t=0$ and chemistry that evolves unambiguously, while field measurements are always complicated by mixing of parcels with different ages. Even relatively small error ratios (absolute residual to total organic mass), such as the $10 \%$ which is typical of the fits resulting from application of this method to ambient data, can be seen in the lab to mask trends that can elucidate SOA formation chemistry. Recent work that builds on the CPCA method by increasing numbers of components considered and parallel work using positive matrix factorization to describe ambient organic MS show that fit quality improves when one includes multiple oxidized-component MS (Lanz et al., 2007; Zhang et al., 2007).

\subsection{Comparison with ambient measurements}

Efforts to understand SOA formation have traditionally focused on the particle-forming potential of a few high-flux, reactive species. Results from laboratory oxidation studies of these species have not generally been qualitatively nor quantitatively congruous with ambient observations. We have shown here and elsewhere the similarity between the component MS observed in our laboratory studies and those calculated from ambient data (Robinson et al., 2007). But the larger question is whether the condensed-phase organic material we study in the lab is chemically representative of that found in the atmosphere. Figure 7 strongly suggests that it is. The figure compares the total final MS of the suspended 
aerosol in our chamber at the end of an experiment (top MS) to the MS of aged material collected downwind of Vancouver, Canada (middle MS) (Alfarra et al., 2004). The laboratory MS is from the experiment with the lowest initial mass concentration (shown in blue in Fig. 1), as this experiment was most representative of ambient aerosol loadings. The bottom spectrum in Fig. 7 is the difference between the top two. A few peaks stand out in this difference spectrum. Most notably, the ambient aerosol is more oxidized than ours, with a higher 44:43 ratio and less mass at higher $m / z$ ratios. However, its most striking characteristic is the absence of major differences outside of those that are to be expected from incomplete oxidation. The inset at the top right of the figure shows that our aerosol is increasingly oxidized with time, and there is no indication that this oxidation has stopped at the end of the experiment. Therefore, with continued oxidant exposure, we would expect the chemical composition of our laboratory aerosol to further converge toward ambient observations.

\section{Conclusions}

Upon exposure to atmospheric oxidants, diluted emissions from a diesel generator react to form substantial amounts of SOA. This chemistry is reflected in changes to the MS of the organic aerosol with increasing oxidant exposure time, and its results can be isolated when the MS of the primary emissions is known. Our analyses reveal that the chemical composition of the SOA formed in these experiments is not constant in time. As an experiment progresses, the SOA (and also, consequently, the total OA) becomes increasingly oxidized. This evolution appears as a progressive shift of signal in the MS over time from higher masses characteristic of unsubstituted hydrocarbons to the smaller masses that indicate more highly functionalized species, and as the increasing dominance of the $\mathrm{CO}_{2}^{+}$fragment at $m / z=44$ with time. At the end of each of our experiments, the residual MS, which is the MS of the non-primary organic mass, closely resembles the oxidized component of organic material that has been observed in several field studies. Additionally, the MS of the total aerosol appears to be asymptotically approaching that of ambient aged organic aerosol.

Overall, the experiments described here form SOA with two features consistent with ambient observations. Both features have been difficult for earlier chamber experiments to match. First, SOA is formed rapidly, quickly reaching a mass loading comparable to the primary organic aerosol mass. Second, the mass spectrum of the SOA is quite highly oxidized and matches the mass spectrum of ambient OOA after a few hours. Both of these features suggest that these experiments may be a good model for OOA formation processes in the atmosphere.

Our results support the hypothesis that the species in an air mass that are responsible for SOA formation change as a function of time. The precursors of early-forming SOA give rise to condensable organics that are less oxidized than those which contribute to later SOA formation, illustrating that vapor pressure has a controlling influence on SOA composition. This influence is only partially captured by considering a compound's oxidation state; molecular weight is also important. Large, saturated semi-volatile species with low vapor pressures may contribute significantly to ambient SOA concentrations. We attribute the SOA formation pattern that we observe to the presence of relatively reduced, but low vapor-pressure species that react to form condensable products. These species likely contribute to rapid, early SOA formation with very high efficiency. Further confirmation of our hypothesis awaits quantification of the atmospheric burdens of these semi-volatile species, laboratory studies of their SOA yields and chemistry, and higher-resolution mass spectrometry data that can better constrain the contribution of primary material to the overall MS in chamber studies.

Acknowledgements. This research was supported by the EPA STAR program through the National Center for Environmental Research (NCER) under grants RD-83108101 and R832162. This paper has not been subject to EPA-required peer and policy review, and therefore does not necessarily reflect the views of the Agency. No official endorsement should be inferred. The PTR-MS and QAMS were acquired with support from the NSF (ATM-0420842). A. M. Sage acknowledges the support of P.E.O. International. We thank Q. Zhang and J. Jimenez for stimulating discussions.

Edited by: R. Cohen

\section{References}

Aiken, A. C., DeCarlo, P. F., Kroll, J. H., Worsnop, D. R., Huffman, J. A., Docherty, K., Ulbrich, I. M., Mohr, C., Kimmel, J. R., Sueper, D., Zhang, Q., Sun, Y., Trimborn, A., Northway, M., Ziemann, P. J., Canagaratna, M. R., Alfarra, R., Prevot, A. S. H., Dommen, J., Duplissy, J., Metzer, A., Baltensperger, U., and Jimenez, J. L.: O/C and OM/OC ratios of primary, secondary, and ambient organic aerosols with high resolution timeof-flight aerosol mass spectrometry, Environ. Sci. Technol., in press, 2008.

Alfarra, M. R., Paulsen, D., Gysel, M., Garforth, A. A., Dommen, J., Prévôt, A. S. H., Worsnopf, D. R., Baltensperger, U., and Coe, H.: A mass spectrometric study of secondary organic aerosols formed from the photooxidation of anthropogenic and biogenic precursors in a reaction chamber, Atmos. Chem. Phys., 6, 52795293, 2006, http://www.atmos-chem-phys.net/6/5279/2006/.

Alfarra, M. R., Coe, H., Allan, J. D., Bower, K. N., Boudries, H., Canagaratna, M. R., Jimenez, J. L., Jayne, J. T., Garforth, A. A., Li, S. M., and Worsnop, D. R.: Characterization of urban and rural organic particulate in the lower Fraser valley using two aerodyne aerosol mass spectrometers, Atmos. Environ., 38, 57455758, 2004.

Allan, J. D., Coe, H., Bower, K., Alfarra, M. R., Delia, A., Jimenez, J. L., Middlebrook, A., Drewnick, F., Onasch, T. B., Canagaratna, M. R., Jayne, J. T., and Worsnop, D. R.: Technical note: 
Extraction of chemically resolved mass spectra from Aerodyne Aerosol mass spectrometer data, J. Aerosol Sci., 35, 922, 2004a. Allan, J. D., Delia, A. E., Coe, H., Bower, K. N., Alfarra, M. R., Jimenez, J. L., Middlebrook, A. M., Drewnick, F., Onasch, T. B., Canagaratna, M. R., Jayne, J. T., and Worsnopf, D. R.: A generalised method for the extraction of chemically resolved mass spectra from aerodyne aerosol mass spectrometer data, J. Aerosol Sci., 35, 909-922, 2004b.

Atkinson, R. and Arey, J.: Atmospheric degradation of volatile organic compounds, Chem. Rev., 103, 4605-4638, 2003.

Bahreini, R., Keywood, M. D., Ng, N. L., Varutbangkul, V., Gao, S., Flagan, R., Seinfeld, J., Worsnop, D. R., and Jimenez, J. L.: Measurements of Secondary Organic Aerosol (SOA) from oxidation of cycloalkenes, terpenes, and m-xylene using an Aerodyne Aerosol Mass Spectrometer, Environ. Sci. Technol., 39, 56745688, doi:10.1021/es048061a, 2005.

Baltensperger, U., Kalberer, M., Dommen, J., Paulsen, D., Alfarra, M., Coe, H., Fisseha, R., Gascho, A., Gysel, M., Nyeki, S., Sax, M., Steinbacher, M., A.S.H., P., Sjogren, S., Weingartner, E., and Zenobi, R.: Secondary Organic aerosols from antrhopogenic and biogenic precursors, Faraday Discuss., 130, 265278, doi:10.1039/b417367h, 2005.

Canagaratna, M. R., Jayne, J. T., Ghertner, D. A., Herndon, S., Shi, Q., Jimenez, J. L., Silva, P. J., Williams, P., Lanni, T., Drewnick, F., Demerjian, K. L., Kolb, C. E., and Worsnop, D. R.: Chase studies of particulate emissions from in-use New York City vehicles, Aerosol Sci. Tech., 38, 555-573, 2004.

Chattopadhyay, S., Tobias, H. J., and Ziemann, P. J.: A method for measuring vapor pressures of low-volatility organic aerosol compounds using a thermal desorption particle beam mass spectrometer, Anal. Chem., 73, 3797-3803, 2001.

de Gouw, J. A., Middlebrook, A. M., Warneke, C., Goldan, P. D., Kuster, W. C., Roberts, J. M., Fehsenfeld, F. C., Worsnop, D. R., Canagaratna, M. R., Pszenny, A. A. P., Keene, W. C., Marchewka, M., Bertman, S. B., and Bates, T. S.: Budget of organic carbon in a polluted atmosphere: Results from the New England Air Quality Study in 2002, J. Geophys. Res., 110, D16 305, doi:10.1029/2004JD005623, 2005.

Goldstein, A. and Galbally, I.: Known and Unexplored Organic Constituents in the Earth's Atmosphere, Environ. Sci. Technol., 41, 1515-1520, 2007.

Hamilton, J., Webb, P., Lewis, A., Hopkins, J., Smith, S., and Davy, P.: Partially Oxidised Organic Components in Urban Aerosol Using GC x GC-TOF/MS, Atmos. Chem. Phys., 4, 1279-1290, 2004,

http://www.atmos-chem-phys.net/4/1279/2004/.

Heald, C., Jacob, D., Park, R., Russell, L., Huebert, B., Seinfeld, J., Liao, H., and Weber, R.: A large organic aerosol source in the free troposphere missing from current models, Geophys. Res. Lett., 32, L18 809, doi:10.1029/2005GL023831, 2005.

Huff Hartz, K. E., Rosenørn, T., Ferchak, S. R., Raymond, T. M., Bilde, M., Donahue, N. M., and Pandis, S. N.: Cloud Condensation Nuclei Activation of Monoterpene and Sesquiterpene Secondary Organic Aerosol, J. Geophys. Res., 110, D14 208, http:// www.agu.org/pubs/crossref/2005.../2004JD005754.shtml, 2005.

Jayne, J. T., Leard, D. C., Zhang, X., Davidovits, P., Smith, K. A., Kolb, C. E., and Worsnop, D. R.: Development of an Aerosol Mass Spectrometer for Size and Composition Analysis of Submicron Particles, Aerosol Sci. Tech., 33, 49-70, 2000.
Jimenez, J. L., Jayne, J. T. Shi, Q., Kolb, C. E., Worsnop, D. R., Yourshaw, I., Seinfeld, J. H., Flagan, R. C., Zhang, X., Smith, K. A., W., M. J., and Davidovits, P.: Ambient aerosol sampling using the Aerodyne Aerosol Mass Spectrometer, J. Geophys. Res. Atmos., 108, 8425, 2003.

Johnson, D., Utembe, S., Jenkin, M., Derwent, R., Hayman, G., Alfarra, M., Coe, H., and McFiggans, G.: Simulating regional scale secondary organic aerosol formation during the TORCH 2003 campaign in the southern UK, Atmos. Chem. Phys., 6, 403418, 2006, http://www.atmos-chem-phys.net/6/403/2006/.

Kalberer, M., Paulsen, D., Sax, M., Steinbacher, M., Dommen, J., Prevot, A. S. H., Fisseha, R., Weingartner, E., Frankevic, V., Zenobi, R., and Baltensperger, U.: Identification of Polymers as Major Components of Atmospheric Organic Aerosols, Science, 303, 1659-1662, 2004.

Kanakidou, M., Seinfeld, J. H., Pandis, S. N., Barnes, I., Dentener, F. J., Facchini, M. C., Van Dingenen, R., Ervens, B., Nenes, A., Nielsen, C. J., Swietlicki, E., Putaud, J. P., Balkanski, Y., Fuzzi, S., Horth, J., Moortgat, G. K., Winterhalter, R., Myhre, C. E. L., Tsigaridis, K., Vignati, E., Stephanou, E. G., and Wilson, J.: Organic aerosol and global climate modelling: a review, Atmos. Chem. Phys., 5, 1053-1123, 2005,

http://www.atmos-chem-phys.net/5/1053/2005/.

Kondo, Y., Miyazaki, Y., Takegawa, N., Miyakawa, T., Weber, R., Jimenez, J. L., Zhang, Q., and Worsnop, D. R.: Oxygenated and water-soluble organic aerosols in Tokyo, J. Geophys. Res. Atmos., 112, D01 203, doi:10.1029/2006JD007056, 2007.

Lanz, V., Alfarra, M., Baltensperger, U., Buchmann, B., Hueglin, C., and Prévôt, A. S. H.: Source apportionment of submicron organic aerosols at an urban site by factor analytical modelling of aerosol mass spectra, Atmos. Chem. Phys., 7, 1503-1522, 2007, http://www.atmos-chem-phys.net/7/1503/2007/.

Lim, Y. B. and Ziemann, P. J.: Products and mechanism of secondary organic aerosol formation from reactions of n-alkanes with $\mathrm{OH}$ radicals in the presence of NOx, Environ. Sci. Technol., 39, 9229-9236, 2005.

Marcolli, C., Canagaratna, M. R., Worsnop, D. R., Bahreini, R., de Gouw, J. A., Warneke, C., Goldan, P. D., Kuster, W. C., Williams, E. J., Lerner, B. M., Roberts, J. M., Meagher, J. F., Fehsenfeld, F. C., Marchewka, M., Bertman, S. B., and Middlebrook, A. M.: Cluster analysis of the organic peaks in bulk mass spectra obtained during the 2002 New England air quality study with an Aerodyne aerosol mass spectrometer, Atmos. Chem. Phys., 6, 5649-5666, 2006, http://www.atmos-chem-phys.net/6/5649/2006/.

Presto, A. A., Huff Hartz, K. E., and Donahue, N. M.: Secondary Organic Aerosol production from terpene ozonolysis: 1. Effect of UV radiation, Environ. Sci. Technol., 39, 7036-7045, http://pubs3.acs.org/acs/journals/doilookup?in_doi= 10.1021/es050174m, 2005.

Robinson, A. L., Donahue, N. M., and Rogge, W. F.: Photochemical Oxidation and Changes in Molecular Composition of Organic Aerosol in the Regional Context, J. Geophys. Res., 111, D03 302, http://www.agu.org/pubs/crossref/2006... /2005JD006265.shtml, doi:10.1029/2005JD006265, 2006.

Robinson, A. L., Donahue, N. M., Shrivastava, M. K., Weitkamp, E. A., Sage, A. M., Greishop, A. P., Lane, T. E., Pierce, J. R., and Pandis, S. N.: Rethinking Organic Aerosols: Semivolatile 
Emissions and Photochemical Aging, Science, 315, 1259-1262, 2007.

Rogge, W. F., Hildemann, L. M., Mazurek, M. A., Cass, G. R., and Simoneit, B. R. T.: Sources of Fine Organic Aerosol. 2. Noncatalyst and Catalyst-Equipped Automobiles and Heavy-Duty Diesel Trucks, Environ. Sci. Technol., 27, 636-651, 1993.

Rudich, Y., Donahue, N. M., and Mentel, T. F.: Aging of organic aerosol: bridging the gap between laboratory and field studies, Annu. Rev. Phys. Chem., 58, 321-352, http://arjournals.annualreviews.org/doi/abs/10.1146/annurev. physchem.58.032806.104432, 2007.

Salcedo, D., Onasch, T. B., Dzepina, K., Canagaratna, M. R., Zhang, Q., Huffman, J. A., DeCarlo, P. F., Jayne, J. T., W., M. J., Worsnop, D. R., Kolb, C. E., Johnson, K. S., Zuberi, B., Marr, L. C., Volkamer, R., Molina, L. T., Molina, M. J., Cardenas, B., Bernabe, R. M., Marquez, C., Gaffney, J. S., Marley, N. A., Laskin, A., Shutthanandan, V., Xie, Y., Brune, W., Lesher, R., Shirley, T., and Jimenez, J. L.: Characterization of ambient aerosols in Mexico City during the MCMA-2003 campaign with Aerosol Mass Spectrometry: results from the CENICA Supersite, Atmos. Chem. Phys., 6, 925-946, 2006, http://www.atmos-chem-phys.net/6/925/2006/.

Schauer, J. J., Kleeman, M. J., Cass, G. R., and Simoneit, B. R. T.: Measurement of emissions from air pollution sources. 2. C-1 through C-30 organic compounds from medium duty diesel trucks, Environ. Sci. Technol., 33, 1578-1587, 1999.

Volkamer, R., Jimenez, J. L., San Martini, F., Dzepina, K., Zhang, Q., Salcedo, D., Molina, L. T., Worsnop, D. R., and Molina, M. J.: Secondary organic aerosol formation from anthropogenic air pollution: Rapid and higher than expected, Geophys. Res. Lett., 33, L17 811, 2006.

Weitkamp, E. A., Sage, A. M., Pierce, J. R., Donahue, N. M., and Robinson, A. L.: Organic Aerosol Formation from Photochemical Oxidation of Diesel Exhaust in a Smog Chamber, Environ. Sci. Technol., 41, 6969-6975, 2007.
Williams, B. J., Goldstein, A. H., Kreisberg, N. M., and Hering, S. V.: An in-situ instrument for speciated organic composition of atmospheric aerosols: Thermal Desorption Aerosol GC/MS-FID (TAG), Aerosol Sci. Tech., 40, 627-638, 2006.

Zhang, J., Huff Hartz, K. E., Pandis, S. N., and Donahue, N. M.: Secondary Organic Aerosol Formation from Limonene Ozonolysis: Homogeneous and Heterogeneous Influences as a Function of $\mathrm{NO}_{x}$, J. Phys. Chem. A, 110, 11 053-11 063, 2006.

Zhang, Q.: Open source CPCA code, http://www.asrc.cestm.albany. edu/qz/, 2005.

Zhang, Q., Alfarra, M. R., Worsnop, D. R., Allan, J., Coe, H., Canagaratna, M. R., and Jimenez, J. L.: Deconvolution and Quantification of Hydrocarbon-like and Oxygenated Organic Aerosols Based on Aerosol Mass Spectrometry, Environ. Sci. Technol., 39, 4938-4952, 2005a.

Zhang, Q., Worsnop, D. R., Canagaratna, M. R., and Jimenez, J. L.: Hydrocarbon-like and oxygenated organic aerosols in Pittsburgh: insights into sources and processes of organic aerosols., Atmos. Chem. Phys., 5, 3289-3311, 2005b.

Zhang, Q., Jimenez, J. L., Canagaratna, M. R., Allan, J. D., Coe, H., Ulbrick, I., Alfarra, M., Takami, A., Middlebrook, A., Sun, Y., K., D., Dunlea, E., Docherty, K., DeCarlo, P. F., Salcedo, D., Onasch, T. B., Jayne, J. T., Miyoshi, T., Shimono, A., Hatakeyama, S., Takegawa, N., Kondo, Y., Schneider, J., Drewnick, F., Weimer, S., Demerjian, K., Williams, P., Bower, K., Bahreini, R., Cottrell, L., Griffin, R., Rautiainen, J., Sun, J., Zhang, Y., and Worsnop, D. R.: Ubiquity and Dominance of Oxygenated Species in Organic Aerosols in AnthropogenicallyInfluenced Northern Hemisphere Mid-latitudes, Geophys. Res. Lett., 34, L13 801, doi:10.1029/2007GL029979, 2007. 